\title{
Secondary production and energetics of the shrimp Caridina nilotica in Lake Victoria, East Africa: model development and application
}

\author{
Marcy Ignatow, Godfrey Mbahinzireki \& John T. Lehman \\ Department of Biology and Center for Great Lakes and Aquatic Sciences, Natural Science Building, University of \\ Michigan, Ann Arbor, MI 48109, USA; Fisheries Research Institute, P.O. Box 343, Jinja, Uganda
}

Received 8 August 1995; in revised form 9 January 1996; accepted 16 February 1996

Key words: tropical zooplankton, bioenergetics, assimilation efficiency

\begin{abstract}
Measurements of body mass, carbon content, respiration, growth, and egestion are combined in a model of secondary production by the tropical freshwater shrimp Caridina. The model is developed to permit its direct application to empirical data for abundances and size frequency distributions of field populations. Model calculations combined with population data for offshore Lake Victoria over a period of two years indicate that Caridina consume the equivalent of $2.2 \%$ of annual lake primary production. Present net annual secondary production by the shrimp is an order of magnitude greater than the present fishery yield of the lake. Detritus-fed experimental organisms evidently had assimilation efficiencies as low as $10 \%$ by model calculation.
\end{abstract}

\section{Introduction}

The atyid shrimp, Caridina nilotica, is a conspicuous inhabitant of many freshwater ecosystems in Africa. A primitive decapod, Caridina attains adult maximum total lengths of $2.5 \mathrm{~cm}$ (Fryer, 1960). Small individuals appear transparent and virtually colorless. Most large specimens are darkly pigmented, appearing primarily dark brown; others are so densely pigmented that they appear dark blue or black.

C. nilotica is abundant in equatorial Lake Victoria, the world's second largest freshwater lake $\left(68800 \mathrm{~km}^{2}\right)$, which has a surface elevation of $1240 \mathrm{~m}$ and a mean annual water temperature of about $25^{\circ} \mathrm{C}$. In African lakes $C$. nilotica has given rise to a slender form with attenuated appendages, which could be correlated with the existence of thick flocculent mud on the bottom of the lake (Fryer, 1960). Caridina is frequently found in littoral regions wherever there are weed beds of submerged vegetation (Fryer, 1960), and it also occurs as an epibenthic, vertically migrating member of the offshore community (Lehman et al., 1996).

Caridina is a primary source of food for juvenile Nile perch (Ogutu-Ohwayo, 1990), and also for birds, mainly heron (Begg, 1973). Nile perch larger than $67 \mathrm{~cm}$ in length have gill raker spacing exceeding the mean body depth of $C$. nilotica, and consequently Hughes (1992) has argued that gill raker spacing is the constraint that prevents perch larger than $70 \mathrm{~cm}$ in length from being effective prawn predators.

Feeding habits of Caridina reportedly include the ingestion of submerged macrophytic vegegation, algae, and plants. Caridina has a complicated and specialized feeding mechanism. Fryer (1960) described Caridina in Lake Victoria as a 'macrophagous chelate raptatory fccder', and as 'detritus feeders, eating the material which accumulates on the bottom of the lake and on submerged macrophytic vegetation'. Fryer's examination of the gut revealed an amorphous mass of graygreen material along with minute alga cells, inorganic particles, and fragments of higher plants. Fryer also reported that the gut fills and empties rapidly, suggesting that the animals rely on a constant abundance of food. Much of the organic matter ingested is loose and flocculent and is released in a partially digested condition or in compact, elongated fecal pellets.

Although Caridina has been characterized as an epibenthic detritivore (Fryer, 1960) and not pelagic in habitat, early surveys have encountered atyid shrimp in 
the plankton (Worthington, 1931). Recent study of $C$. nilotica in Lake Victoria has demonstrated the presence of shrimp not only in littoral regions but in offshore locations as well. Offshore populations (Lehman et al., 1996) were mainly planktonic both day and night and they exhibited diel vertical migration to surface waters in the darkness. Although Fryer characterized littoral Caridina as strict detritivores, Lehman et al. suggest that offshore populations may be facultative consumers of living planktonic algae and other suspended particles, and that the shrimp probably migrate to avoid visual predators.

In this paper we develop a method to calculate the secondary production of pre-reproductive Caridina by application of bioenergetic mass balance modeling. We use the basic equation

$$
I=G+E+R+M,
$$

where $I$ is rate of ingestion, $G$ is growth rate, $E$ is egestion rate, $R$ is the respiration rate and $M$ is molting rate, all expressed in units of carbon mass $(\mu \mathrm{g} \mathrm{C}$ $\mathrm{d}^{-1}$ ). Model development relies heavily on the comprehensive studies of Hart (1980a, 1980b, 1981). We combined Hart's metabolic relationships and equations with original data for abundance and size distributions of Caridina collected from Lake Victoria, and thereby constructed temperature-dependent relationships among age, carapace length, weight, growth, ingestion, egestion, respiration, and molts. From these relationships and data, we developed an algorithm to compute production rates from field data.

\section{Methods}

Model equations for secondary production.

\section{Length and length-weight relationships}

We adopted the empirical length-weight regression developed by Lehman et al. (1996) for Lake Victoria Caridina:

$$
W(\mu \mathrm{gDW})=1.429 L^{3.021}
$$

where $L(\mathrm{~mm})$ is measured from midpoint of the eyes to the base of the telson. We also determined the empirical relationship between individual Caridina length ( $L$, $\mathrm{mm}$ ), and carapace length (CL, $\mathrm{mm}$ ), measured from midpoint of the eyes to the margin of the cephalothorax and urosome, by nonlinear regression $\left(r^{2}=0987, n=\right.$
85; SYSTAT 5.0):

$$
\mathrm{CL}=0.387(\mathrm{SE}=0.029) L^{0.913(\mathrm{SE}=0.037)} .
$$

Animals used to construct the regression were collected from offshore Lake Victoria on 24 October 1992.

\section{Respiration rate}

Hart (1980a) investigated the influence of temperature and body size on oxygen consumption of $C$. nilotica by evaluating changes in routine metabolic rate. $\mathrm{He}$ reported a temperature-dependent regression relationship between oxygen consumption $\left(R, \mu \mathrm{g} \mathrm{O}_{2} \mathbf{h}^{-1}\right)$ and body dry mass $(\mathrm{M}, \mathrm{mg})$ as:

$$
R\left(\mu \mathrm{gO}_{2} \mathrm{~h}^{-1}\right)=0.008 \mathrm{~T}^{1.829} M^{0.830} .
$$

We converted respiration rates by Equation 4 into equivalent carbon units $\left(\mu \mathrm{g} \mathrm{C} \mathrm{d}^{-1}\right)$ by the following relationship:

$R\left(\mu \mathrm{gCd}^{-1}\right)=R\left(\mu \mathrm{gO}_{2} \mathrm{~h}^{-1}\right) \cdot 24 \mathrm{hd}^{-1} \cdot 12 / 32 \cdot 0.949$.

The scaling variables used in Equation 5 represent the ratio of molecular weights of $\mathrm{C}$ to $\mathrm{O}_{2}$ (12:32), and the $R Q$ value of 0.949 for ammonitelic organisms (Downing and Rigler, 1984).

\section{Age, size and growth rates}

Hart (1980b) evaluated growth trajectories and development rates of $C$. nilotica by investigating embryonic durations and post embryonic growth rates at experimental temperatures. We fit a non-linear regression model (SYSTAT 5.0) to Hart's (1980b) weight and age data for C. nilotica at $24^{\circ} \mathrm{C}$ :

$$
W_{\text {rel }}=\exp [c \cdot \text { Age } /(\text { Age }+d)],
$$

where Age is expressed in days, $W_{\text {rel }}=W / W_{0}$ (ratio of dry weight at any age to neonate weight), $c=8.988$ $(\mathrm{SE}=0.081), d=32.630$ ( $\mathrm{SE}=2.017$ ) , and $r^{2}=0.996$. We measured an empirical ratio of $\mathrm{C}: \mathrm{DW}=0.4442$ ( $\mathrm{SE}=0.0056, n=3$ independent samples) for Caridi$n a$ collected from Lake Victoria on 4 April 1995. Carbon body mass at any age $(C)$ can be calculated from relative weight and neonate weight by the equation:

$$
C=0.4442 \cdot W_{\text {rel }} \cdot W_{0} .
$$

Growth rates $(G)$ were calculated by taking the first derivative of Equation 6 and combining with Equation 7: 


$$
\begin{gathered}
G\left(\mu \mathrm{gCd}^{-1}\right)=C \cdot[c /(\text { Age }+d)] \cdot[1- \\
(\text { Age } /(\text { Age }+d)] .
\end{gathered}
$$

\section{Egestion rates}

Hart (1981) estimated egestion rates of Caridina nilotica by quantitative recovery and gravimetric analysis of fecal pellets. His original analysis was reported as a linear regression between egestion rate $(E, \mathrm{mg} \mathrm{DW}$ feces shrimp ${ }^{-1} \mathrm{~d}^{-1}$ ) and $W$ (mg DW) with a positive intercept, thereby potentially overestimating egestion by small juveniles. Hart generously supplied us with his original data, which we subjected to both linear and nonlinear regressions. We found that a linear model was appropriate but that the positive intercept was not significantly different from zero and consequently we substituted a simpler, one-parameter equation (SYSTAT 5.0), relating egestion rate to the dry weight of a shrimp $\left(r^{2}=0.925, n=25\right)$ :

$$
E=0.6825 \cdot W
$$

During April 1995, we collected fecal pellets from Caridina freshly isolated from nearshore Lake Victoria (Napoleon Gulf, Uganda). Feces were dried at $45 \mathrm{C}$ for $24 \mathrm{~h}$ and were subjected to $\mathrm{CHN}$ analysis. Carbon content was $33.77 \%$ of DW. Thus, the egestion rate of Caridina in carbon mass $\left(E_{\mathrm{c}}, \mathrm{mg} \mathrm{C}\right.$ shrimp d$\left.^{-1}\right)$ is:

$$
E_{\mathrm{c}}=0.3377 \cdot 0.6825 \cdot W \text {. }
$$

\section{Molting losses}

Hart and Allanson (1981) reported that the relationship between weight of a molt and carapace length was:

$$
W_{\mathrm{m}}=21 \cdot \mathrm{CL}^{3.086}
$$

where $W_{\mathrm{m}}$ is the dry weight $(\mu \mathrm{g})$ of an exuvium of carapace length CL (mm). According to this relationship, the molts lost by small shrimp equal almost $50 \%$ of their body mass, and larger shrimp have molting losses around $20 \%$ of body mass. The molt losses presented for Caridina seemed to be an unusually large component of the energy budget. By comparison, Parsons et al. (1984) summarized data for Euphausia pacifica and reported that from 7 to $15 \%$ of the animals' food intake could be required for molts.
We re-examined the relationship between molt weight and animal weight for Caridina from Lake Victoria. Live Caridina were collected from Napoleon Gulf, Uganda on 4 April 1995. The animals were sorted individually and were held in Lake Victoria water at ambient laboratory temperature ( 24 to $27 \mathrm{C}$ ). The animals were inspected at ca. $12 \mathrm{~h}$ intervals for up to 72 hours or until molting occurred. Upon molting, both the exuvium and molted animal were collected and were dried at $45^{\circ} \mathrm{C}$ on Teflon disks. The dried specimens were weighed by electrobalance. Analysis showed that the relationship between mass of the molt and the mass of molt and animal combined was linear $\left(r^{2}=0.910, n=11\right)$ over a range of animal masses from $0.4 \mathrm{mg} \mathrm{DW}$ to $18 \mathrm{mg} \mathrm{DW}$ :

$$
W_{\mathrm{m}}=0.138(\mathrm{SE}=0.008) \cdot W .
$$

Carbon content of the molts was $20.7 \%$ ( $\mathrm{SE}=0.4 \%$, $n=3$ independent samples).

Hart (1980b) reported intermolt durations (days) of Caridina nilotica as a function of animal size, sex and temperature (his table 2). We used Hart's data for nonbreeding females at $23.4^{\circ} \mathrm{C}$, which is within $1^{\circ} \mathrm{C}$ of in situ temperatures in Lake Victoria, to determine a schedule of ages at which molting occurs. We divided predicted molt masses $(\mu \mathrm{g})$ by intermolt duration (days) to establish rates associated with molt production (Table 1).

\section{Results}

We developed our production model from published data and equations for pre-reproductive Caridina acclimated at $24^{\circ} \mathrm{C}$. Table 1 reports our estimates for age, weight, respiration rate, growth rate, and rates of egestion, molting, and ingestion for Caridina of specified length. According to Hart (1980b), first reproduction of females usually does not occur in Caridina having total lengths less than $19 \mathrm{~mm}$. Hart's observation coincides with empirical data from Lake Victoria. Offshore populations were composed almost entirely of juveniles (Lehman et al., 1996); only 279 ovigerous females were found among 28073 animals less than $19 \mathrm{~mm}$ length measured from offshore waters (unpublished data).

Assimilation efficiencies were determined using the following equation:

$$
\mathrm{AE}=(G+R+M) /(G+R+E+M),
$$


Table 1. Numerical estimates for mass and metabolic rate functions applied to Caridina in Lake Victoria. $L=$ length (mm), $W=$ dry mass $(\mu \mathrm{g}), C=$ carbon mass ( $\mu \mathrm{g})$. Age (days), $R=$ respiration $\left(\mu \mathrm{g} \mathrm{C} \mathrm{d}^{-1}\right), G=$ growth $\left(\mu \mathrm{g} \mathrm{C} \mathrm{d}^{-1}\right)$, Molt = carbon mass of molt $(\mu \mathrm{g} \mathrm{C})$, $M=$ carbon accumulation for molting $\left(\mu \mathrm{g} \mathrm{C} \mathrm{d}^{-1}\right), E=$ egestion rate $\left(\mu \mathrm{g} \mathrm{C} \mathrm{d}^{-1}\right), \mathrm{AE}=$ assimilation efficiency

\begin{tabular}{|c|c|c|c|c|c|c|c|c|c|}
\hline$L$ & Age & $W$ & $C$ & $G$ & $R$ & $E$ & Molt & $M$ & $\mathrm{AE}$ \\
\hline 2 & 0 & 11.6 & 5.2 & 1.4 & 0.6 & 2.7 & 0 & 0.2 & 0.46 \\
\hline 2.67 & 3.5 & 27.8 & 12.3 & 2.8 & 1.3 & 6.4 & 0.8 & 0.2 & 0.40 \\
\hline 3 & 5.1 & 39.5 & 17.5 & 3.6 & 1.7 & 9.1 & 0 & 0.5 & 0.39 \\
\hline 3.38 & 7.0 & 56.6 & 25.1 & 4.7 & 2.3 & 13.1 & 1.6 & 0.5 & 0.36 \\
\hline 4 & 9.9 & 94.2 & 41.8 & 6.8 & 3.5 & 21.7 & 0 & 0.8 & 0.34 \\
\hline 4.13 & 10.5 & 104 & 46.1 & 7.3 & 3.8 & 23.9 & 3.0 & 0.8 & 0.33 \\
\hline 4.89 & 14.0 & 173 & 76.7 & 10.4 & 5.7 & 39.8 & 4.9 & 1.4 & 0.31 \\
\hline 5 & 14.5 & 185 & 82.1 & 10.8 & 6.1 & 42.6 & 0 & 2.0 & 0.31 \\
\hline 5.78 & 18.1 & 286 & 127 & 14.5 & 8.7 & 66.0 & 8.2 & 2.0 & 0.28 \\
\hline 6 & 19.1 & 320 & 142 & 15.6 & 9.6 & 73.9 & 0 & 3.1 & 0.28 \\
\hline 6.67 & 22.2 & 441 & 196 & 19.1 & 12.5 & 102 & 12.6 & 3.1 & 0.25 \\
\hline 7 & 23.7 & 511 & 227 & 20.9 & 14.1 & 118 & 0 & 4.5 & 0.25 \\
\hline 7.55 & 26.3 & 642 & 285 & 24.1 & 17.0 & 148 & 18.3 & 4.5 & 0.24 \\
\hline 8 & 28.5 & 764 & 340 & 26.7 & 19.7 & 176 & 0 & 5.6 & 0.23 \\
\hline 8.56 & 31.1 & 938 & 416 & 30.1 & 23.3 & 216 & 26.8 & 5.6 & 0.21 \\
\hline 9 & 33.3 & 1091 & 485 & 32.7 & 26.5 & 252 & 0 & 7.6 & 0.21 \\
\hline 9.54 & 36.0 & 1301 & 578 & 36.0 & 30.6 & 300 & 37.2 & 7.6 & 0.20 \\
\hline 10 & 38.5 & 1500 & 666 & 38.7 & 34.5 & 346 & 0 & 10.1 & 0.19 \\
\hline 10.48 & 40.9 & 1728 & 768 & 41.6 & 38.8 & 399 & 49.4 & 10.1 & 0.19 \\
\hline 11 & 43.8 & 2000 & 889 & 44.6 & 43.8 & 461 & 0 & 11.7 & 0.18 \\
\hline 11.51 & 46.5 & 2294 & 1019 & 47.7 & 49.1 & 529 & 65.5 & 11.7 & 0.17 \\
\hline 12 & 49.4 & 2602 & 1156 & 50.4 & 54.5 & 600 & 0 & 14.9 & 0.17 \\
\hline 12.48 & 52.1 & 2929 & 1301 & 53.1 & 60.1 & 676 & 83.7 & 14.9 & 0.16 \\
\hline 13 & 55.4 & 3313 & 1472 & 55.8 & 66.6 & 764 & 0 & 18.5 & 0.16 \\
\hline 13.39 & 57.6 & 3623 & 1609 & 58.0 & 71.7 & 836 & 103 & 18.5 & 0.15 \\
\hline 14 & 61.7 & 4145 & 1841 & 60.7 & 80.2 & 956 & 0 & 15.6 & 0.14 \\
\hline 14.75 & 66.5 & 4852 & 2155 & 64.3 & 91.4 & 1119 & 139 & 15.6 & 0.13 \\
\hline 15 & 68.5 & 5105 & 2268 & 65.1 & 95.3 & 1177 & 0 & 19.8 & 0.13 \\
\hline 15.98 & 75.3 & 6181 & 2745 & 69.1 & 111.7 & 1426 & 177 & 19.8 & 0.12 \\
\hline 16 & 75.8 & 6204 & 2756 & 68.8 & 112.0 & 1431 & 0 & 16.7 & 0.12 \\
\hline 17 & 83.6 & 7451 & 3310 & 71.8 & 130.4 & 1719 & 0 & 16.7 & 0.11 \\
\hline 17.78 & 89.8 & 8532 & 3790 & 74.2 & 146.0 & 1968 & 244 & 16.7 & 0.11 \\
\hline 18 & 92.2 & 8855 & 3934 & 74.1 & 150.5 & 2043 & 0 & 21.4 & 0.11 \\
\hline 19 & 101.5 & 10427 & 4632 & 75.5 & 172.4 & 2405 & 0 & 21.4 & 0.10 \\
\hline 19.34 & 104.4 & 11001 & 4886 & 76.3 & 180.2 & 2537 & 314 & 21.4 & 0.10 \\
\hline
\end{tabular}

where all variables are in rates of carbon $\left(\mu \mathrm{g} \mathrm{C} \mathrm{d}^{-1}\right)$. Assimilation efficiencies of Caridina were found to range from less than $50 \%$ to as low as $10 \%$, and mean calculated assimilation efficiency during juvenile development, $2 \mathrm{~mm}$ to $19 \mathrm{~mm}$, was $19 \%$. These low assimilation efficiencies were calculated from data for Hart's experimental animals maintained on a diet of detritus, thus indicating that most of the detritus is not readily digestible to these organisms.

\section{In situ secondary production}

We computed the biomass ( $\mathrm{mg} \mathrm{C} \mathrm{m} \mathrm{m}^{-2}$ ), net production (NP: growth + molt production, $\mathrm{mg} \mathrm{C} \mathrm{m}^{-2} \mathrm{~d}^{-1}$ ) total gross production (GP: growth + molts + respiration, $\left.\mathrm{mg} \mathrm{C} \mathrm{m}^{-2} \mathrm{~d}^{-1}\right)$ and ingestion rate $\left(\mathrm{I}_{\text {tot }}\right.$ : growth + molts + respiration + egestion) for offshore Caridina populations in Lake Victoria from our model estimates (Table 1) combined with empirical determinations of 
abundance and size distributions (Lehman et al., 1996). Caridina lengths were measured to the nearest $1 \mathrm{~mm}$ (midpoint of eyes to base of telson) and relative frequencies by size class were used to weight the rate functions for the population. The total population rate of respiration ( $R_{\mathrm{tot}}, \mathrm{mg} \mathrm{C} \mathrm{m}^{-2} \mathrm{~d}^{-1}$ ), for example, was calculated as:

$$
R_{\mathrm{tot}}=N \cdot \Sigma\left(f_{i} R_{i}\right)
$$

where $f_{i}$ is relative frequency of size class $i$ and $R_{i}$ is the respiration rate for individuals in size class $i . N$ is total population abundance (individuals $\mathrm{m}^{-2}$ ). Population estimates of growth, molting, egestion, and ingestion were calculated, as well.

The total net production (NP) of the population was calculated by

$$
\mathrm{NP}=G_{\mathrm{tot}}+M_{\mathrm{tot}}
$$

where $G_{\mathrm{tot}}$ is the total growth rate, and $M_{\mathrm{tot}}$ is the total molting rate. The total gross production (GP) of the population was calculated by

$$
\mathrm{GP}=G_{\mathrm{tot}}+R_{\mathrm{tot}}+M_{\mathrm{tot}}
$$

where $R$ is the total respiration rate. The total ingestion or consumption rate of the population was calculated by the equation:

$$
I_{\mathrm{tot}}=G_{\mathrm{tot}}+E_{\mathrm{tot}}+R_{\mathrm{tot}}+M_{\mathrm{tot}} .
$$

Table 2 shows representative calculations for Lake Victoria data, and Figure 1 summarizes biomass and production rates from 1992 to 1994 based on empirical abundances and size frequency distributions, combined with the model equations given here. We found the average NP of Caridina for the years studied to be $11.4(\mathrm{SE}=3.6, n=19) \mathrm{mg} \mathrm{C} \mathrm{m}^{-2} \mathrm{~d}^{-1}$, the average $\mathrm{GP}=20.1(\mathrm{SE}=6.4, n=19)$, and the average $I_{\text {tot }}=$ $112.2(\mathrm{SE}=35.9, n=19) \mathrm{mg} \mathrm{C} \mathrm{m}^{-2} \mathrm{~d}^{-1}$.

\section{Discussion}

Mugidde (1993) compared the seasonality of present and past daily integral productivity of phytoplankton in offshore Lake Victoria. She found the average productivity to be $13.9 \mathrm{~g} \mathrm{O}_{2} \mathrm{~m}^{-2} \mathrm{~d}^{-1}$, which is 5213 (i.e., $13900 \cdot 12 / 32) \mathrm{mg} \mathrm{Cm}^{-2} \mathrm{~d}^{-1}$. Mugidde's modern measurements are about double those reported by Talling (1965). Comparison of our estimates of total population rates of ingestion $\left(\mathrm{I}_{\mathrm{tot}}\right)$ by Caridina with Mugidde's estimates for primary production gives evidence

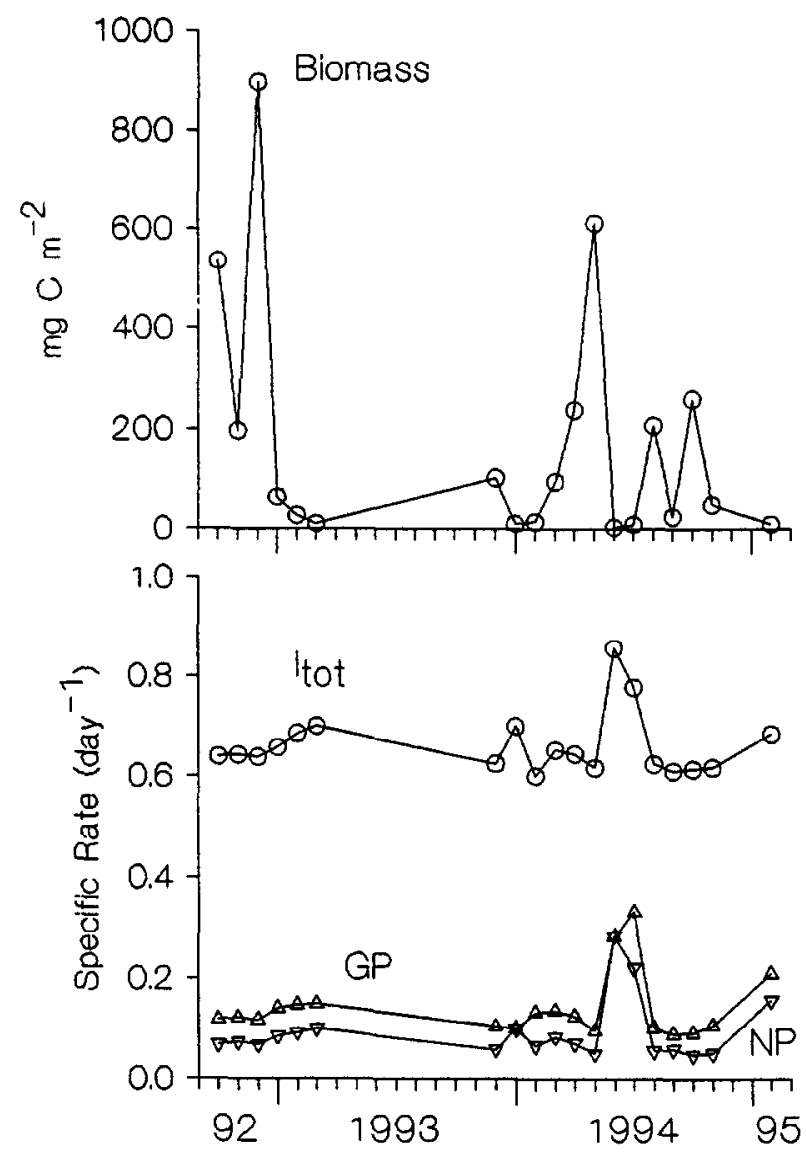

Figure 1. Biomass $\left(\mathrm{mg} \mathrm{C} \mathrm{m}^{-2}\right)$ and ratios of secondary production

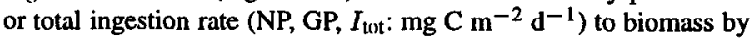
Caridina at an offshore reference station in Lake Victoria south of Bugaia Island, Uganda (Station BG: $0^{\circ} 3.16^{\prime} \mathrm{S}, 33^{\circ} 16.59^{\prime} \mathrm{E}$; depth = $62 \mathrm{~m})$.

that if Caridina acts exclusively as a detritus feeder, it consumes a small fraction $(2.2 \%)$ of annual lake primary production, and assimilates only about onefifth of that. On the other hand, if the shrimp ever act as facultative zooplanktivores in offshore regions, our estimates for ingestion rates by Caridina could translate into a substantial predation effect on zooplankton prey.

Conversely, net production by Caridina appears to represent a significant potential forage resource for planktivorous fish in Lake Victoria. Our average figure of $11.4 \mathrm{mg} \mathrm{C} \mathrm{m}^{-2} \mathrm{~d}^{-1}$ for net production is substantially larger than historical and recent estimated fishery yields. Ligtvoet and Witte (1991) report that total annual fishery yields for Lake Victoria have ranged from roughly 100,000 to 400,000 tons per year. These estimates represent 4 to $16 \mathrm{mg}$ fish wet weight $\mathrm{m}^{-2} \mathrm{~d}^{-1}$ averaged over the entire lake. Assuming that $\mathrm{C}$-content 
Table 2. Representative calculations for offshore Lake Victoria Caridina sampled 27 October 1992 at $0930 \mathrm{~h}$ from $60 \mathrm{~m}$ to surface. Column sums are weighted by relative frequencies of each size class $\left(f_{i}\right)$ and totals per $\mathrm{m}^{2}$ are calculated from the measured areal abundance of Caridina (1474 individuals $\mathrm{m}^{-2}$ ). $\Sigma f_{i} \cdot X_{i}$ is the frequency-weighted summation for each column

\begin{tabular}{|c|c|c|c|c|c|c|}
\hline $\begin{array}{l}L \\
(\mathrm{~mm})\end{array}$ & $f_{i}$ & $\begin{array}{c}C_{i} \\
(\mu \mathrm{g} \mathrm{C})\end{array}$ & $\begin{array}{c}G_{i} \\
\left(\mu \mathrm{g} \mathrm{Cd}^{-1}\right)\end{array}$ & $\begin{array}{c}R_{i} \\
\left(\mu \mathrm{g} \mathrm{Cd}^{-1}\right)\end{array}$ & $\begin{array}{c}E_{i} \\
\left(\mu \mathrm{g} \mathrm{C} \mathrm{d}^{-1}\right)\end{array}$ & $\begin{array}{c}M_{i} \\
\left(\mu \mathrm{g} \mathrm{C} \mathrm{d}^{-1}\right)\end{array}$ \\
\hline 2 & 0.005 & 5.2 & 1.4 & 0.6 & 2.7 & 0.2 \\
\hline 3 & 0.016 & 17.5 & 3.6 & 1.7 & 9.1 & 0.5 \\
\hline 4 & 0.033 & 41.8 & 6.8 & 3.5 & 21.7 & 0.8 \\
\hline 5 & 0.096 & 82.1 & 10.8 & 6.1 & 42.6 & 2.0 \\
\hline 6 & 0.146 & 142 & 15.6 & 9.6 & 73.9 & 3.1 \\
\hline 7 & 0.112 & 227 & 20.9 & 14.1 & 118 & 4.5 \\
\hline 8 & 0.225 & 340 & 26.7 & 19.7 & 176 & 5.6 \\
\hline 9 & 0.101 & 485 & 32.7 & 26.5 & 252 & 7.6 \\
\hline 10 & 0.050 & 666 & 38.7 & 34.5 & 346 & 10.1 \\
\hline 11 & 0.022 & 889 & 44.6 & 43.8 & 461 & 11.7 \\
\hline 12 & 0.096 & 1156 & 50.4 & 54.5 & 600 & 14.9 \\
\hline 13 & 0.022 & 1472 & 55.8 & 66.6 & 764 & 18.5 \\
\hline 14 & 0.039 & 1841 & 60.7 & 80.2 & 956 & 15.6 \\
\hline 15 & 0.016 & 2268 & 65.1 & 95.3 & 1177 & 19.8 \\
\hline 16 & 0.011 & 2756 & 68.8 & 112.0 & 1431 & 16.7 \\
\hline 17 & 0 & 3310 & 71.8 & 130.4 & 1719 & 16.7 \\
\hline 18 & 0 & 3934 & 74.1 & 150.5 & 2043 & 21.4 \\
\hline 19 & 0 & 4632 & 75.5 & 172.4 & 2405 & 21.4 \\
\hline \multirow[t]{5}{*}{$\Sigma f_{i} \cdot X_{i}$} & & 516 & 28.4 & 26.1 & 267.7 & 6.9 \\
\hline & $N$ & $C_{\text {tot }}$ & $G_{\mathrm{tot}}$ & $R_{\mathrm{tat}}$ & $E_{\mathrm{tot}}$ & $M_{\mathrm{tht}}$ \\
\hline & Indiv & mg C & $\mathrm{mg} \mathrm{C}$ & $\mathrm{mg} \mathrm{C}$ & $\mathrm{mg} \mathrm{C}$ & $\mathrm{mg} \mathrm{C}$ \\
\hline & $m^{-2}$ & $\mathrm{~m}^{-2}$ & $\mathrm{In}^{-2} \mathrm{~d}^{-1}$ & $m^{-2} d^{-1}$ & $\mathrm{III}^{-2} \mathrm{~d}^{-1}$ & $\mathrm{III}^{-2} \mathrm{~d}^{-1}$ \\
\hline & 1474 & 760 & 41.8 & 38.4 & 394.6 & 10.2 \\
\hline \multicolumn{7}{|c|}{$\mathrm{NP}=G_{\mathrm{tot}}+M_{\mathrm{tot}}=52.0 \mathrm{mg} \mathrm{C} \mathrm{m}^{-2} \mathrm{~d}^{-1}$} \\
\hline \multicolumn{7}{|c|}{$\mathrm{GP}=G_{\mathrm{tot}}+M_{\mathrm{tot}}+R_{\mathrm{tot}}=90.4 \mathrm{mg} \mathrm{C} \mathrm{m}^{-2} \mathrm{~d}^{-1}$} \\
\hline \multicolumn{7}{|c|}{$I_{\mathrm{tot}}=G_{\mathrm{tot}}+M_{\mathrm{tot}}+R_{\mathrm{tot}}+E_{\mathrm{tot}}=485 \mathrm{mg} \mathrm{C} \mathrm{m}^{-2} \mathrm{~d}^{-1}$} \\
\hline
\end{tabular}

is about $5 \%$ of wet weight, these fish yields correspond to 0.2 to $0.8 \mathrm{mg} \mathrm{C} \mathrm{m}^{-2} \mathrm{~d}^{-1}$, more than 10-fold less than the average daily rate of Caridina production. In other words, the net biomass production by Caridina may be more than 10 times greater than the present fishery yield of the lake, which makes the shrimp quantitatively significant as a forage resource.

Our estimates for Caridina production are based on a time series of measurements from a single deep reference station in the Ugandan waters of offshore Lake Victoria, where the primary production measurements were conducted. More precise comparisons with lakewide fishery production should await com- plete spatial surveys for Caridina, with estimates for biomass and secondary production.

The rate functions from our model, presented in Table 2, provide the information needed to calculate biomass and secondary production by Caridina populations from abundance and size frequency data. The rates are applicable to tropical water temperatures of ca. 23 to $24{ }^{\circ} \mathrm{C}$ and can provide a means to convert survey data on standing crop biomass into production and ingestion rates. We believe that the model-derived numerical results presented here provide a convenient algorithm for assessment of production dynamics of an ecologically important freshwater crustacean. 


\section{Acknowledgements}

We thank Donna Lehman, Arni Litt, and the staff of the Uganda Fisheries Research Institute, Jinja, Uganda, for laboratory and logistical assistance. Prof. R. C. Hart kindly provided some of his original data for analysis, and made helpful comments about the manuscript. This research was supported by U.S. National Science Foundation grant DEB-9318035, and by a grant from the NOAA National Undersea Research Program.

\section{References}

Begg, G. W., 1973. The feeding habits of the whitewinged Black Tern on Lake Kariba. Ostrich 44: 149-153.

Downing, J. A. \& F. H. Rigler, 1984. A manual for the assessment of secondary productivity in fresh waters. Blackwell.

Fryer, G., 1960. The feeding mechanism of some atyid prawns of the genus Caridina. Trans. Roy. Soc. Edin. 64: 217-244.

Hart, R. C., 1980a. Oxygen consumption in Caridina nilotica (Decapoda: Atyidae) in relation to temperature and size. Freshwat. Biol. 10: 215-222.

Hart, R. C., 1980b. Embryonic duration, and post-embryonic growth rates of the tropical freshwater shrimp Caridina nilotica (Decapoda: Atyidae) under laboratory and experimental field conditions. Freshwat. Biol. 10: 297-315.
Hart, R. C., 1981. Population dynamics and production of the tropical freshwater shrimp Caridina nilotica (Decapoda: Atyidae) in the littoral of Lake Sibaya. Freshwat. Biol. 11: 531-547.

Hart, R. C. \& B. R. Allanson, 1981. Energy requirements of the tropical freshwater shrimp Caridina nilotica (Decapoda: Atyidae). Verh. Int. Ver. Limnol. 21: 1597-1602.

Hughes, N. F., 1992. Nile perch, Lates niloticus, predation on the freshwater prawn, Caridina nilotica in the Nyanza Gulf, Lake Victoria, East Africa. Envir. Biol. Fish. 33: 307-309.

Lehman, J. T., G. B. Mbahinzireki \& L. M. Ndawula, 1996. Caridina nilotica in Lake Victoria: abundance, biomass, and diel vertical migration. Hydrobiologia 317: 177-182.

Ligtvoet, W. \& F. Witte, 1991. Perturbation through predator introduction: effects on the wood web and fish yields in Lake Victoria (East Africa). In O. Ravera (ed.), Perturbation and recovery of terrestrial and aquatic ecosystems. Elliss Horwood Ltd., Chichester: 263-268.

Mugidde, R., 1993. The increase in phytoplankton primary productivity and biomass in Lake Victoria (Uganda). Verh. Int. Ver. Limnol. 25: 846-849.

Ogutu-Ohwayo, R., 1990. Changes in the prey ingested and the variations in the Nile perch and other fish stocks of Lake Kyoga and the northern waters of Lake Victoria (Uganda). J. Fish Biol. 37: 55-63.

Parsons, T. R., M. Takahashi \& B. Hargrave, 1984. Biological Oceanographic Processes, 3rd edn. Pergamon Press, 330 pp.

Talling, J. F., 1965. The photosynthetic activity of phytoplankton in East African lakes. Int. Revue ges. Hydrobiol. 50: 1-32.

Worthington, E. B., 1931. Vertical movements of fresh-water macroplankton. Int. Rev. ges. Hydrobiol. 25: 394-436. 